Anim. Reprod., v.16, n.2, p.297-301, Apr./Jun. 2019

\title{
Vitrified embryo transfer in Merino sheep under extensive conditions
}

\section{Alejandro Gibbons ${ }^{1, \S}$, Macarena Bruno-Galarraga ${ }^{1}$, Jimena Fernandez ${ }^{1}$, Antonio Gonzalez-Bulnes ${ }^{2}$, Marcela Cueto ${ }^{1}$}

\author{
${ }^{1}$ Laboratorio de Reproducción de Rumiantes Menores, INTA Bariloche, San Carlos de Bariloche, Argentine. \\ ${ }^{2}$ Departamento de Reproducción Animal, SGIT-INIA, Madrid, Spain.
}

\begin{abstract}
The aim was to evaluate pregnancy success after transfer of embryos vitrified in micropipette tips in Merino sheep under extensive conditions. A second objective was to evaluate the influence of embryo stage in such pregnancy rate. One hundred and twenty-seven embryos were rewarmed and transferred into recipient ewes. On rewarming, the embryos were placed into three-step cryoprotectant dilutions. Finally, prior to transfer to recipient females, embryos were maintained in Basic Medium for $5 \mathrm{~min}$ at $25^{\circ} \mathrm{C}$ and were reevaluated by morphological criteria; all degenerated embryos were eliminated. Recipient ewes $(n=150)$ were treated for estrus with sponges placed for 14 days and $300 \mathrm{IU}$ of eCG. At embryo transfer, three experimental groups were defined: morulae transferred on Day 7, blastocysts transferred on Day 7 and blastocysts transferred on Day 8 after sponge removal. In all groups, semi-laparoscopic transfer of one rewarmed embryo per recipient was performed. Pregnancy was diagnosed by ultrasonography on day 28 after embryo transfer. The embryo selection rate after rewarming was higher for blastocysts $(89.3 \%-67 / 75)$ compared to morulae $(65.9 \%-60 / 91)(\mathrm{P}<0.05)$. Pregnancy diagnosis showed a $38.3 \%$ (23/60) of success after morula transfer on Day 7 post progestagen removal. The day of transfer showed a significant influence on pregnancy rate after blastocyst transfer (Day 8, 55.9\% - 19/34 vs Day 7, 21.2\% - 7/33) $(\mathrm{P}<0.05)$. Blastocysts transfer on Day 8 showed the highest global efficiency (pregnancies/total embryos after rewarming) $(47.5 \%$ - 19/40) $(\mathrm{P}<0.05)$. In conclusion, reproductive efficiency obtained by vitrified embryo transfer allows its recommendation for embryo transfer programs under extensive conditions. The importance of considering the synchrony between the embryo age and the recipient uterus stage is emphasized.
\end{abstract}

Keywords: Vitrification, cryosurvival, in vivo-produced embryos

\section{Introduction}

The first lamb born following transfer of a vitrified embryo was reported by Széll et al. (1990). Afterwards, in sheep and other species, vitrification of embryos was in the focus of intense research (Schiewe et al., 1991; Ali and Shelton, 1993; Brown and Radcievic, 1999) and several methodologies were developed. Among them, we can highlight the use of electron microscopy grids (Martino et al., 1996), fine capillaries (Vajta et al., 1997), cryo-loops (Lane et al., 1999), cryo-tops (Kuwayama and Kato, 2000), straws (Baril et al., 2001) and micropipette tips (Cremades et al., 2004; Gibbons et al., 2011).

However, in spite of these efforts, there is scarce transfer of the vitrification technology in sheep embryos from the bench to the field. The technique has not been extensively used because there is no standard procedure and because limited reports on fertility under field conditions are available (Green et al., 2009; Gibbons et al., 2011).

Hence, the main objective of this study was to evaluate, in Merino sheep under extensive conditions, the pregnancy success obtained after transfer of embryos which were vitrified using a technique previously developed at our laboratory (micropipettes tips; Gibbons et al., 2011). A second objective was to evaluate the influence of embryo stage at vitrification (morula or blastocyst) in such pregnancy rate, since previous studies in classical freezing protocols have addressed a lower survival of morulae to cryopreservation (Garcia-Garcia et al., 2006).

\section{Materials and methods}

Ethical concerns were taken into account by adhering to local animal welfare regulations and practices. The present study complies with national and international standards regarding the use of animals for experimentation and it has been approved under the rules of the Regional Institutional Committee for the Care and Use of Animals of Experimentation (CICUAE-PATNOR INTA, Disposition 066/17 Resolution 533/16).

A total of 174 multiparous Merino sheep, 4-6 years old were used in the experiment, 24 ewes were used as embryo donors and 150 ewes were used as embryo recipients. The experiment was conducted during the natural breeding season (May-Jun, HS) in two locations. Embryo donors were kept at the Experimental Station of the Instituto Nacional de Tecnología Agropecuaria (INTA), Bariloche, Río Negro state, Argentine (latitude $41^{\circ} 07^{\prime} 23^{\prime \prime} \mathrm{S}$, longitude $71^{\circ}$ $15^{\prime} 12$ ' W), under natural day-length. Animals were kept under intensive management and received 1.300 $\mathrm{g} / \mathrm{ewe}$ /day of concentrate (homemade mixture with 18\% of crude protein) for having a moderate body condition $(2.7 \pm 0.1$, subjective scale, 1 emaciated, 5 obese) (Russel et al., 1969). Water was provided ad libitum.

Embryo recipients were kept at the Experimental Farm of the INTA, Bariloche, Río Negro $\left(41^{\circ} 73^{\prime}\right.$ ' $\left.\mathrm{S}, 70^{\circ} 43^{\prime} 12^{\prime \prime} \mathrm{W}\right)$, under natural grazing 
on pastures and with free access to water. Body condition score was $2.6 \pm 0.0$. The paddock had an area of 243.8 hectares dominated by a grassy shrub steppe with a forage production of $100 \mathrm{~kg} / \mathrm{ha} /$ year.

Briefly, the study design consisted on the recovery of embryos from donor sheep on days 7 and 8 after sponge removal (Section Superovulation, artificial insemination and embryo recovery in donor ewes) Immediately after recovery, embryos were assessed, vitrified and then rewarmed (Section Assessment, vitrification and rewarming of embryos). At embryo transfer, three experimental groups of recipient ewes were defined: morulae transferred on Day 7, blastocysts transferred on Day 7 and blastocysts transferred on Day 8 (Section Synchronization of estrous cycle, embryo transfer and pregnancy diagnosis in recipient ewes). Detailed procedures are presented in the next sections.

\section{Superovulation, artificial insemination and embryo recovery in donor ewes}

The estrous cycle of embryo donors was synchronized by the insertion of intravaginal progestagen sponges $(60 \mathrm{mg}$ of medroxyprogesterone acetate, MAP; Progespon ${ }^{\circledR}$, Syntex, Argentine), for 14 days (Day 0: day of sponge insertion). The superovulatory treatment, adapted from Gibbons et al. (2010), consisted of the administration of a reduced dose of $80-\mathrm{mg}$ pFSH in six decreasing doses $(18 \mathrm{mg} \mathrm{x}$ 2; $14 \mathrm{mg}$ x 2; $8 \mathrm{mg}$ x 2, i.m.; Folltropin- $\mathrm{V}^{\circledR}$, Bioniche, Canada), injected twice daily from the morning of Day 12 to $12 \mathrm{~h}$ after pessary removal. A single dose of equine Chorionic Gonadotropin (200 IU of eCG, i.m.; Novormon $^{\circledR}$, Syntex, Argentine) was administered concomitantly with the fifth FSH dose and the pessary removal.

Estrus detection was performed with vasectomized adult rams, twice daily ( 8 a.m. and 8 p.m.) from 24 to $60 \mathrm{~h}$ after pessary removal. Twelve hours after estrus detection, ewes were artificially inseminated with 100 million frozen-thawed spermatozoa from the same batch and ram (post-thaw progressive forward motility 40-45\%). Half of each semen dose was introduced into each uterine horn by laparoscopic method, using a cannula for intrauterine artificial insemination (Aspic for ewe insemination, 23-G needle, IMV $^{\circledR}, L^{\prime}$ Aigle, France).

Embryo recovery was performed by surgical laparotomy on Days $7(\mathrm{n}=12)$ and $8(\mathrm{n}=12)$ after progestagen removal for obtaining morulae and blastocysts. Females fasted $24 \mathrm{~h}$ prior, were anaesthetized with xylazine $\left(0.2 \mathrm{mg} / \mathrm{kg}\right.$, i.m.; Kensol ${ }^{\circledR}$ $2 \%$, Konig, Argentine) and ketamine hydrochloride (2.5 mg/kg, i.m.; Ketalar ${ }^{\circledR}$, Parke-Davis, Argentine). In addition, a local anesthetic (lidocaine, $1 \mathrm{ml}$, i.m.; Frankaina $^{\circledR}$ 2\%; Fatro Von Franken, Argentine) was administered at the site of the surgery on the midline of the abdomen. In brief, laparotomy was performed flushing each uterine horn with $20 \mathrm{ml}$ of commercial embryo recovery medium (Vigro Complete Flush ${ }^{\circledR}$, Bioniche, USA), pre-warmed to $38^{\circ} \mathrm{C}$ and supplemented with $10 \%$ adult bovine serum
(Internegocios ${ }^{\circledR}$, Argentine). Embryo recovery medium was injected by a sterile syringe with an 18-G blunt needle, inserted close to the uterine horn bifurcation and directed from the uterine horn toward the utero-tubal junction, where a catheter was attached with silk $(3 / 0$, Ethicon $^{\circledR}$, Brazil). The catheter consisted of a pediatric nasogastric tube $(\mathrm{k} 33)$ fastened to a blunt needle $(50 / 20)$, with a central opening at the tip and two lateral openings. Once embryo recovery was finished, surgical incisions were closed by suture. General antibiotic was administered in the form of oxytetracycline $(1 \mathrm{ml} / 10 \mathrm{~kg}$ im), and local antibiotic (gentamicine) was applied at the site of the abdominal incision. Immediately after embryo recovery, a single IM injection of $125-\mu \mathrm{g}$ Cloprostenol (Estrumate ${ }^{\circledR}$, Intervet Schering Plough, Argentine) was administered to induce corpora lutea (CL) regression

\section{Assessment, vitrification and rewarming of embryos}

All embryos were kept at $25^{\circ} \mathrm{C}$ in holding solution (Syngro ${ }^{\circledR}$, Bioniche, USA) and evaluated just after recovery by morphological criteria (IETS, 1998), using a stereomicroscope (Olympus SZ, Olympus Optical Co., LTA., Japan); only embryos in morula and blastocyst stages classified as grade 1 (excellent) or grade 2 (good) were selected for vitrification in micropipette tips, using the methodology described by Gibbons et al. (2011).

Vitrification and rewarming procedures were performed using a basic medium (BM) comprising commercial flushing medium (Bovi-pro ${ }^{\circledR}$, Minitube, USA) supplemented with $20 \%$ fetal bovine serum (FBS $^{\circledR}$, Internegocios, Argentine). Other chemicals used for embryo vitrification and rewarming were purchased from Sigma Chemical Co. (St. Louis, MO, USA).

For vitrification, briefly, all embryos were exposed to three different solutions at room temperature, according to the following procedure: (i) $\mathrm{BM}+10 \%$ glycerol $(\mathrm{G})$ for $5 \mathrm{~min}$, (ii) $\mathrm{BM}+10 \% \mathrm{G}+$ $20 \%$ ethylene glycol (EG) for $5 \mathrm{~min}$ and (iii) $\mathrm{BM}+25 \%$ $\mathrm{G}+25 \% \mathrm{EG}$ (vitrification solution) for $30 \mathrm{~s}$. Embryos were then aspirated using an automatic $10 \pm 0.1 \mu \mathrm{l}$ micropipette (Eppendorf, USA) and loaded in $1.5 \mu \mathrm{l}$ vitrification solution into the lumen of plastic tips $(2$ embryos/tip; $10 \pm 0.1 \mu \mathrm{l}$ micropipette tips, Eppendorf Inc., USA). After removal from the micropipette, tips were introduced into $3.6 \mathrm{ml}$ cryo-tubes (Nunc, Denmark) which were filled with liquid nitrogen and stored in a liquid nitrogen container for one month prior rewarming.

On rewarming, the micropipette tips were warmed between the thumb and middle fingers for $10 \mathrm{~s}$ and then embryos were immersed in different solutions at $25^{\circ} \mathrm{C}$ in three dilution steps for $5 \mathrm{~min}$ each, to allow the removal of the intracellular cryoprotectant: i) $\mathrm{BM}+$ $12.5 \% \mathrm{G}+12.5 \% \mathrm{EG}+0.5 \mathrm{M}$ sucrose; ii) $\mathrm{BM}+0.5 \mathrm{M}$ sucrose and iii) $\mathrm{BM}+0.25 \mathrm{M}$ sucrose. Finally, prior to transfer to recipient females, embryos were maintained in $\mathrm{BM}$ for $5 \mathrm{~min}$ at $25^{\circ} \mathrm{C}$ and were re-evaluated by morphological criteria; all degenerated embryos were eliminated (D'Alessandro and Martemucci, 2016). 
Synchronization of estrous cycle, embryo transfer and pregnancy diagnosis in recipient ewes

The estrous cycle of the 150 recipient Merino ewes were synchronized by the insertion of intravaginal progestagen sponges $(60 \mathrm{mg}$ of medroxyprogesterone acetate, MAP; Progespon ${ }^{\circledR}$, Syntex, Argentine) for 14 days plus a dose of eCG (300 IU of eCG, i.m.; Novormon $^{\circledR}$, Syntex, Argentine) at progestagen removal.

At embryo transfer, three experimental groups were defined by combining embryo stage and day after progestagen removal in the recipients: morulae transferred on Day 7 (Morula-TD 7 Group; $\mathrm{n}=60$ embryos), blastocysts transferred on Day 7 (Blastocyst-TD Group; $\mathrm{n}=33$ embryos) and blastocysts transferred on Day 8 (Blastocyst-TD 8 Group; $\mathrm{n}=34$ embryos). Because it was decided to assign the largest number of embryos to each of the experimental groups, the Morula- $\mathrm{TD}_{8}$ group was not constituted. Transfer procedure was carried out under general and local anesthesia and using antibiotic administration described in last section in all groups.

Firstly, the presence of at least one CL was assessed by laparoscopy. In the responding ewes, a small laparotomy (around $1 \mathrm{~cm}$ ) was made on the midline of the abdomen, cranial to the udder. The end of the uterine horn corresponding to the ovary bearing the CL was exposed using a non-traumatic clamp and, following its puncture with a $18-\mathrm{G}$ needle, one embryo per recipient (Green et al., 2009) was placed into the lumen of the uterine horn by using a piston pipette for embryo transfer (Assipettor $^{\circledR}$, Minitüb, Germany). The uterine horn was then allowed to return into the abdomen and laparotomy was closed by suture. All embryo transfers were performed within 30 min after cryoprotectant removal.

On Day 28 after embryo transfer, pregnancy diagnosis was performed by transrectal ultrasonography with a $5 \mathrm{MHz}$ linear array transducer (Aloka 500SSD, Japan), and pregnant ewes were allowed to lamb naturally.

Statistical analysis

This study was designed to compare the reproductive success of embryo transfer in sheep, taking into account the stage of embryo development and day of embryo transfer after progestagen removal. Data analysis was carried out using the CATMOD procedure of SAS (SAS, 2003). CATMOD analyzes categorical data using a linear model similar to ANOVA. Statistical significance was accepted from $\mathrm{P}<0.05$. Results were expressed as the mean \pm standard error.

\section{Results}

A total of 189 embryos were recovered from the 24 donor ewes $(7.9 \pm 1.0$ embryos/ewe) on day 7 $(46.6 \%$ - 88/189) and day 8 (53.4\% - 101/189) after pessary removal. Of these 189 embryos, 166 were selected as grades 1 and 2 for vitrification (87.8\%), 91 morulae $(54.8 \%$ - 91/166) and 75 blastocysts $(45.2 \%$ 75/166).

After rewarming, a total of 127 embryos were found to be morphologically normal for transfer $(76.5 \%$; $127 / 166$, transferred embryos/vitrified embryos), carrying out a total of 127 embryo transfers in recipient females.

When the presence of at least one CL was evaluated by laparoscopy, a total of 13 ewes were discarded because of the absence of CL. Ten recipient ewes were not used because there were no available embryos

The embryo selection rate post rewarming was higher for blastocysts compared to morulae $(89.3 \%$ $67 / 75$ vs $65.9 \%-60 / 91 ; \mathrm{P}<0.05)$.

Pregnancy diagnosis showed a $38.3 \%$ of success after morula transfer on Day 7 after progestagen removal (Table 1). While day of transfer showed a significant influence on yields obtained after blastocyst transfer (55.9\% of pregnancies in the Blastocyst- $\mathrm{TD}_{8}$ Group vs $21.2 \%$ in the Blastocyst- $\mathrm{TD}_{7}$ Group; $\mathrm{P}<0.05$ ).

When considering the total number of pregnancies in relation to the total number of rewarmed embryos, Blastocyst-TD 8 Group (47.5\%) showed the highest global efficiency in relation to the Morula- $\mathrm{TD}_{7}$ $(25.3 \%)$ and Blastocyst- $\mathrm{TD}_{7}$ Groups $(20.0 \%)(\mathrm{P}<0.05)$.

All pregnancies were carried to term and no post partum mortality was observed.

Table 1. Reproductive efficiency of ovine embryos vitrified and transferred according to embryo stage and day after progestagen removal in recipient ewes.

\begin{tabular}{lcccc}
\hline \multicolumn{1}{c}{ Group $^{1}$} & $\begin{array}{c}\text { Selection rate } \\
\text { after rewarming }\end{array}$ & $\begin{array}{c}\text { Recipients }^{3} \\
(\mathrm{n})\end{array}$ & $\begin{array}{c}\text { Pregnancy rate } \\
(\%)\end{array}$ & $\begin{array}{c}\text { Global } \\
\text { efficiency }^{4}(\%)\end{array}$ \\
\hline${\text { Morula- } \mathrm{TD}_{7}}$ & $60 / 91(65.9)^{\mathrm{a}}$ & 60 & $23 / 60(38.3)^{\mathrm{ab}}$ & $23 / 91(25.3)^{\mathrm{a}}$ \\
Blastocyst-TD $_{7}$ & $33 / 35(94.3)^{\mathrm{b}}$ & 33 & $7 / 33(21.2)^{\mathrm{a}}$ & $7 / 35(20.0)^{\mathrm{a}}$ \\
Blastocyst-TD $_{8}$ & $34 / 40(85.0)^{\mathrm{b}}$ & 34 & $19 / 34(55.9)^{\mathrm{b}}$ & $19 / 40(47.5)^{\mathrm{b}}$ \\
\hline
\end{tabular}

${ }^{\mathrm{a}, \mathrm{b}}$ : Different letters in the same column indicate $\mathrm{P}<0.05$ (CATMOD procedure, SAS 2003); ${ }^{1}$ Morula-TD ${ }_{7}$, morulae transferred on Day 7; Blastocyst- $\mathrm{TD}_{7}$, blastocysts transferred on Day 7; Blastocyst- $\mathrm{TD}_{8}$, blastocysts transferred on Day $8 ;{ }^{2}$ Selected embryos/Total embryos after rewarming; ${ }^{3}$ Only transferred recipients; ${ }^{4}$ Pregnancies/Total embryos after rewarming.

\section{Discussion}

The results of the present study indicate that vitrification/rewarming procedure is a reliable method to be applied in sheep maintained under extensive rearing, but conditioning factors derived from embryo stage and day of transfer should be considered.

Embryo stage was firstly critical for survival rate after vitrification/rewarming and, overall, blastocysts showed better percentages of cryotolerance 
than morulae ( 89.3 vs $65.9 \%)$. These percentages are similar to previously reported for morulae $(70 \%$; Songsasen et al., 1995) and blastocysts (84\%; Dattena et al., 2000). However, Gibbons et al. (2011) obtained similar selection rates of transferable embryos after rewarming, independently of embryo stage (89.5 and $85.7 \%$ for morulae and blastocysts, respectively). The relatively low survival rate in morulae after vitrification/rewarming in relation to blastocysts indicates that the blastocyst stage has a higher survival to vitrification procedures, in agreement with GarciaGarcia et al. (2006), who indicated that survival rates following conventional freezing improve as embryo stage progresses.

Embryo stage was also critical for pregnancy success, although modulated by the day of estrous cycle of the recipient at embryo transfer. The pregnancy rate obtained after transfer of embryos at morula stage on Day 7 after progestagen removal was around $40 \%$, providing evidence for the hypothesis that vitrification could be an alternative to increase viability in early stages of embryo development (Vajta, 2000). In addition, cryotolerance rate for the vitrification/rewarming procedure was higher $(65.9 \%)$ than for classical freezing ( $46.3 \%$ reported by GarciaGarcia et al., 2006).

The pregnancy rate after blastocyst transfer was strongly affected by day of transfer, being higher for blastocysts transferred on Day 8 than for blastocysts transferred on Day 7 after progestagen removal, in agreement with previous data on vitrified embryos in sheep (Naitana et al., 1995). These data support hypotheses addressing the critical role of an accurate synchrony between the embryo stage and the estrous cycle of the recipient female, and questioning the adequacy of blastocyst transfer at a fixed time of 7 days after sponge removal and eCG administration.

The need of synchrony between the embryo stage and the day of the estrous cycle was early postulated by Rowson and Moor (1966) for embryo transfer in the bovine species and, afterwards, data in cattle and sheep indicated that a close synchronization between embryo age and uterine stage of the recipient is a prerequisite for normal development of transferred embryos. In cattle, it has been reported that the transfer of a day- 7 fresh embryo to a day-5 uterus or a day- 8 uterus conditions pregnancy rate (Randi et al., 2016). In sheep, results in recipient ewes after the transfer of vitrified blastocysts on Days 6,7 and 8 after estrus detection (days 7, 8 and 9 after sponge removal) were $72.7,90.0$ and $54.5 \%$ for pregnancy rates and $72.7,80.0$ and $45.5 \%$ for lambing rates (Naitana et al., 1995).

The results of the present study, when transferring morulae on Day 7 or blastocysts on Day 8, are similar to previously obtained in terms of both survival (50\%; Baril et al., 2001) and pregnancy rates (55.8\%; Green et al., 2009), but lower than those reported by other authors $(62.9 \%$ lambing rate; Dattena et al., 2000); although we have to note that these last authors only transferred blastocysts that re-expanded after vitrification/rewarming.

Our results confirm that blastocyst transfer on
Day 8 after progestagen removal is related to higher cryosurvival and pregnancy rates, as previously reported (Széll et al., 1990; Mc Ginnis and Youngs, 1990; Garcia-Garcia et al., 2005). Overall, global efficiency after blastocyst transfer on Day 8 after pessary removal $(47.5 \%)$, indicates that embryo viability following cryopreservation improves as embryo developmental stage progresses. On the other hand, although rates of selection and pregnancy after vitrified morula transfer are acceptable, when considering both rates together, it is necessary to point out that a low global efficiency is observed $(25.3 \%)$.

Concomitantly, using fresh embryos, Rizzo et al. (2012) reported that best yields were obtained when transferring two blastocysts to recipient ewes with more than two corpora lutea. However, in our study, only one embryo was transferred by recipient, and pregnancy rates were similar to that obtained by transferring two embryos per recipient female in the same experimental conditions (around 41 and 50\% viable fetuses/transferred embryos for morulae and blastocysts, respectively; Gibbons et al., 2011). This finding is of great interest due to the higher perinatal mortality of twins when compared to single lambs under extensive production conditions ( 75 and $90 \%$ of lamb survival for twin and single lambs, respectively, Fernandez Abella, 2015), which would penalize the final yields obtained by the transfer of two embryos.

In conclusion, the acceptable reproductive efficiency obtained by transferring morulae on Day 7 or blastocysts on Day 8 after progestagen removal, at a proportion of one embryo per recipient ewe, allows recommending the use of this technique for embryo transfer programs performed under extensive field conditions.

The highest pregnancy rate in relation to the total number of rewarmed embryos was achieved by transferring embryos in the blastocyst stage on Day 8 after progestagen removal, such findings emphasize the importance of considering the synchrony between the age of the embryo and the stage of the recipient uterus.

\section{Acknowledgment}

The present study was supported by the Project PNSA 1115053 (INTA). The authors thank to the staff of the Experimental farm Pilcaniyeu of INTA Bariloche for assistance during the study.

\section{References}

Ali J, Shelton JN. 1993. Successful vitrification of day6 sheep embryos. J Reprod Fertil, 99:65-70.

Baril G, Traldi AL, Cognie Y, Leboeuf B, Beckers JF, Mermillod P. 2001. Successful direct transfer of vitrified sheep embryos. Theriogenology, 56:299-305.

Brown BW, Radcievic T. 1999. Production of sheep embryos in vitro and development of progeny following single and twin embryo transfer. Theriogenology, 51:105-116.

Cremades N, Sousa M, Silva J, Viana P, Sousa S, Oliveira C, Teixeira da Silva J, Barros A. 2004. 
Experimental vitrification of human compacted morulae and early blastocysts using fine diameter or plastic micropipettes. Hum Reprod, 19:300-305.

D'Alessandro, AG, Martemucci, G. 2016. Superovulatory response to gonadotrphin $\mathrm{FSH} / \mathrm{LH}$ treatment and effect of progestin supplement to recipients on survival of transferred vitrified embryos in goats. Theriogenology, 85:296-301.

Dattena M, Ptak G, Loi P, Cappai P. 2000. Survival and viability in vitro and in vivo produced ovine blastocysts. Theriogenology, 53:1511-1519.

Fernandez Abella D. 2015. Mortalidad neonatal de corderos. Tecnologías reproductivas bovinas y ovinas. Editorial Hemisferio Sur, Montevideo, Uruguay. pp.2746.

Garcia-Garcia RM, Gonzalez-Bulnes A, Dominguez V, Veiga-Lopez A, Cocero MJ. 2005. Culture of early stage ovine embryos to blastocyst enhances survival rate after cryopreservation. Theriogenology, 63:2233-2242.

Garcia-Garcia RM, Gonzalez-Bulnes A, Dominguez V, Veiga-Lopez A, Cocero MJ. 2006. Survival of frozen-thawed sheep embryos cryopreserved at cleavage stages. Cryobiology, 52:108-113.

Gibbons AE, Pereyra-Bonnet FP, Escobar L, Cueto M.I. 2010. Eficiencia de un tratamiento de ovulación múltiple con dosis reducida de FSH-p en ovejas Merino. In Abstracts of the Segundas Jornadas Internacionales del Instituto de Investigación y Tecnología en Reproducción Animal (INITRA), Buenos Aires, Argentina: Fac Cs Vet, UBA. Buenos Aires. InVet 12. pp.268.

Gibbons AE, Cueto MI, Pereyra-Bonnet FP. 2011. A simple vitrification technique for sheep and goat embryo cryopreservation. Small Rumin Res, 95:61-64.

Green RE, Santos BFS, Sicherle CC, LandimAlvarenga FCD, Bicudo SD. 2009. Viability of OPS vitrified sheep embryos after direct transfer. Reprod Dom Anim, 44:406-410.

International Embryo Transfer Society (IETS). 1998. In Stringfellow DA (Ed). Manual of the International Embryo Transfer Society. Seidel SM. IL, USA. pp 106-107.

Kuwayama M, Kato O. 2000. All-round vitrification method for human oocytes and embryos. J Assist Reprod Genet, 17:477-485.

Lane M, Schoolcraft WB, Gardner DK, Phil D. 1999. Vitrification of mouse and human blastocysts using a novel cryoloop container-less technique. Fertil Steril, 72:1073-1078.

Martino A, Songsasen N, Leibo SP. 1996.
Development into blastocysts of bovine oocytes cryopreserved by ultra-rapid cooling. Biol Reprod, 54:1059-1069.

Mc Ginnis LK, Youngs CR. 1990. Vitrification of ovine embryos. Theriogenology, 33:287.

Naitana S, Dattena M, Gallus M, Loi P, Branca A, Ledda S, Cappai P. 1995. Recipient synchronization affects viability of vitrified ovine blastocysts. Theriogenology, 43:1371-1378.

Randi F, Fernandez-Fuertes B, Mc Donald M, Forde N, Kelly AK, Bastos-Amorin HB, Muniz de Lima EM, Morotti F, Seneda MM, Lonergan P. 2016. Asynchronous embryo transfer as a tool to understand embryo-uterine interaction in cattle: is a large conceptus a good thing?. Reprod Fertil Dev, 28:19992006.

Rizzo H, Francois D, Fassier T, Guitton E, Baril G, Cognie J, Fatet A, Guignot F, Mermillod P, Petit JP, Beckers JF, Remy B, Foucras G, Meyer G. 2012. Transferência de embriões como ferramenta para formação de rebanho experimental ovino e análise dos fatores que podem maximizar a multiplicação do plantel. Rev Bras Reprod Anim, 36:62-65.

Rowson LEA, Moor RM. 1966. Embryo transfer in the sheep: The significance of synchronizing oestrus in the donor and recipient animal. J Reprod Fertil, 11:207212.

SAS. 2003. User's Guide, Version 8. Statistical Analysis System Institute Inc., Cary, NC.

Russel AJF, Doney JM, Gunn RG. 1969. Subjective assessment of body fat in live sheep. $J$ Agric Sci, 72:451-454.

Schiewe MC, Rall WF, Stuart LD, Wildt DE. 1991 Analysis of cryoprotectant cooling rate and in situ dilution using conventional freezing or vitrification for cryopreserving sheep embryos. Theriogenology, 36:279293.

Songsasen N, Buckrell BC, Plante C, Leibo SP. 1995. In vitro and in vivo survival of cryopreserved sheep embryos. Cryobiology, 32:78-91.

Széll A, Zhang J, Hudson R. 1990. Rapid cryopreservation of sheep embryos by direct transfer into liquid nitrogen vapour at $180 \quad{ }^{\circ} \mathrm{C}$. Reprod Fertil Dev, 2:613-618.

Vajta G, Booth PJ, Holm P, Greve T, Callesen H. 1997. Successful vitrification of early stage bovine in vitro produced embryos with the Open Pulled Straw (OPS) method. Cryo-Letters, 18:191-195.

Vajta G. 2000. Vitrification of the oocytes and embryos of domestic animals. Anim Reprod Sci, 60:357-364. 